\title{
Oxygen Tension and Inhaled Nitric Oxide Modulate Pulmonary Levels of S-Nitrosocysteine and 3-Nitrotyrosine in Rats
}

\author{
SCOTT A. LORCH, DAVID MUNSON, RICHARD T. LIGHTFOOT, AND HARRY ISCHIROPOULOS \\ The Joseph Stokes Jr. Research Institute [S.A.L., D.M., R.T.L.], Children's Hospital of Philadelphia, \\ Philadelphia, Pennsylvania, 19104, U.S.A., and Department of Biochemistry and Biophysics [H.I.], The \\ University of Pennsylvania, Philadelphia, Pennsylvania, 19104
}

\begin{abstract}
The oxidative environment within the lung generated upon administration of oxygen may be a critical regulator for the efficacy of inhaled nitric oxide therapy, possibly as a consequence of changes in nitrosative and nitrative chemistry. Changes in S-nitrosocysteine and 3-nitrotyrosine adducts were therefore evaluated after exposure of rats to $80 \%$ or $>95 \%$ oxygen for 24 or $48 \mathrm{~h}$ with and without $20 \mathrm{ppm}$ inhaled nitric oxide. Exposure to $80 \%$ oxygen led to increased formation of S-nitrosocysteine and 3-nitrotyrosine adducts in lung tissue that were also associated with increased expression of iNOS. The addition of inhaled nitric oxide in $80 \%$ oxygen exposure did not alter any of these adducts in the lung or in the bronchoalveolar lavage (BAL). Exposure to $>95 \%$ oxygen led to a significant decrease in S-nitrosocysteine and an increase in 3-nitrotyrosine adducts in the lung. Co-administration of inhaled nitric oxide with $>95 \%$ oxygen prevented the decrease in S-nitrosocysteine levels. The levels of S-nitrosocysteine and 3-nitrotyrosine returned to baseline in a time-dependent fashion after termination
\end{abstract}

\section{ABSTRACT}

of exposure to $>95 \%$ oxygen and inhaled nitric oxide. These data suggest the formation of S-nitrosating and tyrosine-nitrating species is regulated by oxygen tensions and co-administration of inhaled nitric oxide restores the nitrosative chemistry without a significant impact upon the nitrative pathway. (Pediatr Res 56: 345-352, 2004)

3NT, 3-nitrotyrosine

\section{Abbreviations}

BAL, bronchoalveolar lavage

CLD, chronic lung disease

ECMO, extracorporeal membrane oxygenation

NO, nitric oxide

eNOS, endothelial nitric oxide synthase

iNOS, inducible nitric oxide synthase

nNOS, neuronal nitric oxide synthase

PPHN, persistent pulmonary hypertension

SNO, S-nitrosothiol
Inhaled nitric oxide (NO) is a relatively new but established therapeutic modality for the treatment of a variety of respiratory diseases in neonates such as PPHN and CLD. Clinical trials utilizing inhaled NO for the treatment of PPHN have shown improved arterial oxygen tension and decreased ECMO utilization with similar mortality rates (1-4). The use of inhaled NO has been shown to improve oxygenation in premature infants with severe hypoxemic respiratory failure (5), and a preliminary study of infants with established CLD has shown both a reduced supplemental oxygen requirement and improved arterial oxygen tension in 11 of 16 infants (6). More recently, Schreiber et al. (7) have demonstrated a decrease in

Received November 21, 2003; accepted March 24, 2004.

Correspondence: Harry Ischiropoulos, Ph.D., Joseph Stokes Jr. Research Institute, Children's Hospital of Philadelphia, 3516 Civic Center Blvd., 416D Abramson Research Center, Philadelphia, PA 19104, U.S.A.; e-mail: ischirop@mail.med.upenn.edu

Supported by National Institutes of Health, National Heart, Lung, and Blood Institute grant number HL-54926 and a Forrest Pharmaceutical Advancing Neonatal Care Grant.

DOI: 10.1203/01.PDR.0000134256.30519.9B death and chronic lung disease in premature infants given inhaled NO.

One of the concerns regarding the use of inhaled NO in conjunction with hyperoxia has been the potential of forming secondary reactive nitrogen species $(8-10)$. Hyperoxia induces the formation of reactive oxygen species, which may consume NO, preventing its therapeutic effects. The reactive nitrogen species formed may also contribute to oxidative injury, and evidence for protein oxidation and nitration has been accumulating in experimental models of hyperoxia-induced lung injury. In particular, hyperoxia has been found to cause damage to alveolar epithelium and endothelium $(11,12)$, and extensive nitration in airway epithelium and alveolar interstitium has been noted in female mice exposed to hyperoxia (13). Recently, in a model of hyperoxia in newborn rats, macrophages were demonstrated to play a significant role in the generation of reactive oxygen species and 3-nitrotyrosine (14). Peroxidases may also contribute to the formation of nitrative species $(15,16)$, and myeloperoxidase specifically has been implicated 
in the generation of 3-nitrotyrosine in a rat model of hyperoxia (17). Despite the anticipation that protein nitration may be further augmented by inclusion of inhaled NO, inhalation of 20 ppm in the mouse model failed to show any significant increase in nitrated proteins (13). Inhalation of NO at $20 \mathrm{ppm}$ or less has actually been associated with a reduction in local inflammatory events and prolonged survival during hyperoxia $(18,19)$.

Another NO-mediated protein modification is the Snitrosation of cysteine residues yielding SNO. This protein modification may profoundly regulate the reactivity of NO by directly altering the activity of nitrosated proteins, or possibly by consuming NO, thereby decreasing the formation of nitrating species. The number of proteins identified that are regulated by nitrosation continues to grow, and there is mounting evidence that nitrosative chemistry plays a significant role in signaling processes including regulation of cell homeostasis and survival (20-24). Previous studies have shown that Snitrosocysteine adducts are increased with the use of inhaled NO with or without concurrent hyperoxia (13).

The effects of different oxygen tensions in modulating the formation of nitrosating and nitrating species within the lung remain largely unexplored with the exception of one small clinical study that has reported a positive correlation between premature infant plasma 3-nitrotyrosine levels and supplemental oxygen (25). Moreover, the effect of returning to room air after exposure to hyperoxia and inhaled NO on the dynamic changes of NO-mediated protein modifications has not been evaluated. This study explored the effects of exposure to $80 \%$ and $>95 \%$ oxygen in the presence or absence of inhaled $\mathrm{NO}$ administration on the regional distribution within the lung of S-nitrosocysteine and 3-nitrotyrosine and quantified the changes of $\mathrm{NO}$ adducts over time in BAL, plasma, and lung tissue. The same indices were assessed 24 and $48 \mathrm{~h}$ after return to room air.

\section{METHODS}

Adult Fisher 344 male rats were treated with one of six conditions: 1) room air ( $21 \%$ inhaled oxygen concentration); 2 ) 20 ppm inhaled NO; 3) $80 \%$ inhaled oxygen; 4) $80 \%$ inhaled oxygen plus $20 \mathrm{ppm}$ inhaled NO; 5) $>95 \%$ inhaled oxygen; or 6) $>95 \%$ inhaled oxygen plus $20 \mathrm{ppm}$ inhaled NO. Eight animals were assigned to the room air control group, and six animals were treated in each experimental condition. Oxygen was provided through canisters of the desired concentration of oxygen prepared by the manufacturer. Inhaled NO was provided through $400 \mathrm{ppm}$ canisters titrated through an INOvent analyzer (INO Therapeutics, Inc., Clinton, NJ). Concentrations of each gas as well as nitrogen dioxide were monitored during the experiment using chemiluminescence methodology. All animals were housed in a sealed Plexiglas container with positive pressure instillation of both study gases. Feeding was ad libitum. The institutional animal care and use committee of the Children's Hospital of Philadelphia approved this project.

For each of the experimental conditions, animals were treated for either 24 or $48 \mathrm{~h}$ and then killed after anesthesia with pentobarbital. Study samples were obtained after anesthesia but before death. For one group of animals treated with
$>95 \%$ inhaled oxygen plus $20 \mathrm{ppm}$ inhaled NO, the experimental condition was stopped after $24 \mathrm{~h}$ and the animals allowed to recover on room air for 24 or $48 \mathrm{~h}$ before anesthesia and sacrifice. After anesthesia with pentobarbital, a tracheostomy tube was placed under direct visualization. BAL was then performed by instilling $30 \mathrm{~mL} / \mathrm{kg}$ of $50 \mathrm{mM}$ PBS directly into the tracheostomy tube, divided into two aliquots. Lung tissue was then obtained through saline washing of the tissue, removal en bloc, and fixation of one lung in 4\% paraformaldehyde in PBS. The other lung was snap frozen in liquid nitrogen. Finally, whole blood was obtained in heparinized test tubes under direct cardiac puncture and centrifuged at $500 \times g$ for 10 min. Fifty microliters of plasma and BAL fluid was placed in a buffered solution of $5 \mathrm{mM} \mathrm{N}$-ethylmaleimide and $100 \mathrm{uM}$ diethylenetriaminepentaacetate (DTPA) for measurement of SNO levels. The rest of the sample was set aside for nitrate and nitrite measurements.

Measurement of SNO. Protein SNO and low-molecularweight SNO were measured by a chemiluminescence-based assay through the reaction of NO with ozone. Five milliliters of $50 \mathrm{mM}$ potassium iodine in glacial acetic acid were placed in the purge container of the Sievers 280 chemiluminescence analyzer (Sievers Instruments, Boulder, CO, U.S.A.). Sulfanilamide was added to each sample at a final concentration of $0.1 \%$ to eliminate nitrite. Ten microliters of the unknown sample, either plasma or BAL fluid, were injected into the purge container. The reading in millivolts was compared with a standard curve using SNO-glutathione, obtaining a concentration of SNO. This value was then standardized to the protein concentration of the sample assessed via colorimetric techniques using a Bio-Rad protein assay (Bio-Rad, Hercules, CA, U.S.A.).

Measurement of nitrate and nitrite. Nitrite and nitrate levels were measured by the same chemiluminescence techniques using $5 \mathrm{~mL}$ of $0.05 \mathrm{M}$ vanadium chloride mixed with 1 $\mathrm{N} \mathrm{HCl}$ in the purge vessel of the Sievers 280 chemiluminescence analyzer heated to $97^{\circ} \mathrm{C}$. Ten microliters of the unknown sample, either plasma or BAL fluid, were injected into the purge container. The reading in millivolts was compared with a standard curve generated with authentic nitrate and nitrite, obtaining a combined concentration of nitrate plus nitrite.

Immunohistochemical analysis of lung tissue. Paraffinized lung tissue was deparaffinized and stained with either rabbit polyclonal anti-3NT antibodies as developed by Viera et al. (26) or rabbit polyclonal anti-SNO antibodies as developed by Geffard et al. (27) as previously described (13). 3-Nitrotyrosine staining was confirmed with a polyclonal anti-3NT antibody (polyclonal 432) raised against a synthetic peptide as described previously (28). Fluorescently tagged goat anti-rabbit secondary antibodies were used to localize 3NT and SNO signal within the lung tissue. Fab fragments of these secondary antibodies were used to minimize nonspecific Fc binding to lung macrophages. Slides were examined using an Olympus (Tokyo, Japan) fluorescence-inverted microscope and random areas were quantified with the Metamorph imaging system (Universal Imaging Corporation, Downington, PA) under 20× magnification. Dithionite or mercuric chloride was used to create negative controls. 
Additional samples were stained with polyclonal anti-iNOS antibodies (Transduction Laboratories, Lexington, KY, U.S.A.) at 1:1000 dilution after antigen retrieval in boiling sodium citrate. Antibody binding was visualized by use of Vector goat anti-rabbit secondary antibody and a Vector Elite $\mathrm{ABC}$ staining kit (Vector Laboratories, Burlingame, CA, U.S.A.) for DAB according to the manufacturer's instructions. The sections were counterstained with hematoxylin and mounted for light microscopy. One section for each animal was treated without primary antibody as a negative control.

Statistical methods. Nonparametric statistical methods were used to compare measurements of SNO and nitrite/nitrate levels between experimental groups and the room air controls. To assess the effects of individual treatments on these measurements, ordinary least-squares regression analysis was used via Stata version 7.0 (StatSoft, College Station, TX, U.S.A.). Image quantification of immunohistochemically stained slides was analyzed using nonparametric statistical techniques and compared with room air controls.

\section{RESULTS}

S-nitrosocysteine adducts. The SNO adducts in the BAL fluid collected in a solution of $N$-ethylmaleimide and DTPA were evaluated by potassium iodide/iodine reduction and gas phase chemiluminescence detection in sulfanilamide treated samples. Data in Figure 1 reveal that treatment with $80 \%$ oxygen for $48 \mathrm{~h}$ resulted in a significant increase in SNO levels compared with room air control animals, and that coadministration of inhaled NO did not change these levels. In contrast, exposure to $>95 \%$ oxygen for the same time resulted in a significant decline to nearly undetectable levels. The co-administration of inhaled $\mathrm{NO}$ with $>95 \%$ oxygen resulted in SNO levels comparable to baseline control levels after $24 \mathrm{~h}$ of exposure. In animals maintained in room air, treatment with inhaled NO increased SNO levels by an average of $60 \%$ in BAL.

The quantitative assessment of SNO adducts in BAL appears to be reflective of changes in the lung tissue as determined by immunohistochemical evaluation of the regional distribution of SNO adducts (Fig. 2). Increased staining in the bronchial and alveolar tissue as compared with controls was observed in the lung tissue of animals treated with $80 \%$ oxygen. Consistent with the decline of SNO adducts in BAL, exposure to $>95 \%$ oxygen revealed a significant decrease (statistically significant when analyzed digitally with MetaMorph software) in the staining in both bronchial and alveolar tissue. Addition of inhaled NO to animals exposed to $80 \%$ oxygen did not increase staining, whereas inhaled NO in the presence of $>95 \%$ oxygen increased SNO staining in bronchial airway epithelium. Pretreatment of the lung tissue with $\mathrm{HgCl}$ eliminated the binding of the anti-S-nitrosocysteine antibody, demonstrating the specificity of staining.

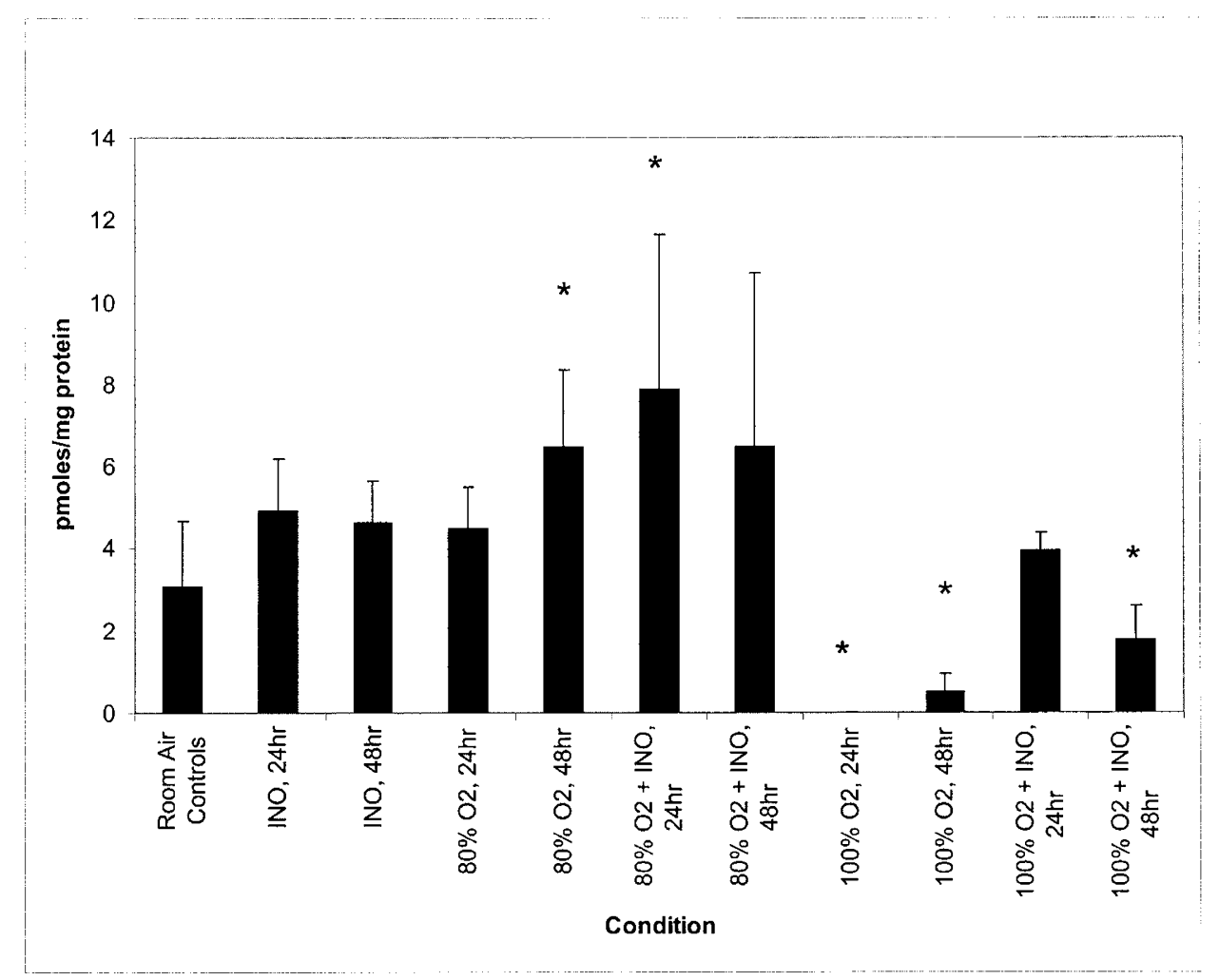

Figure 1. Quantification of S-nitrosocysteine and low-molecular-weight SNO in BAL fluid of animals treated with $80 \%$ or $>95 \%$ oxygen with or without 20 ppm inhaled NO. Data reported as pmol SNO/mg of protein. ${ }^{*} p<0.05$ compared with room air controls by nonparametric rank sum test. Ordinary least-squares regression was used to evaluate the independent effects of oxygen concentration and inhaled NO treatment on SNO in BAL fluid. Exposure to $80 \%$ oxygen was found to significantly increase SNO levels in the BAL when used for $48 \mathrm{~h}(n=6, p<0.001)$. Exposure to $>95 \%$ oxygen, though, was found to decrease $\mathrm{SNO}$ levels in BAL $(n=6, p<0.001)$. Inhaled NO treatment increased SNO levels in the BAL independent of oxygen concentration $(p<0.001)$. 

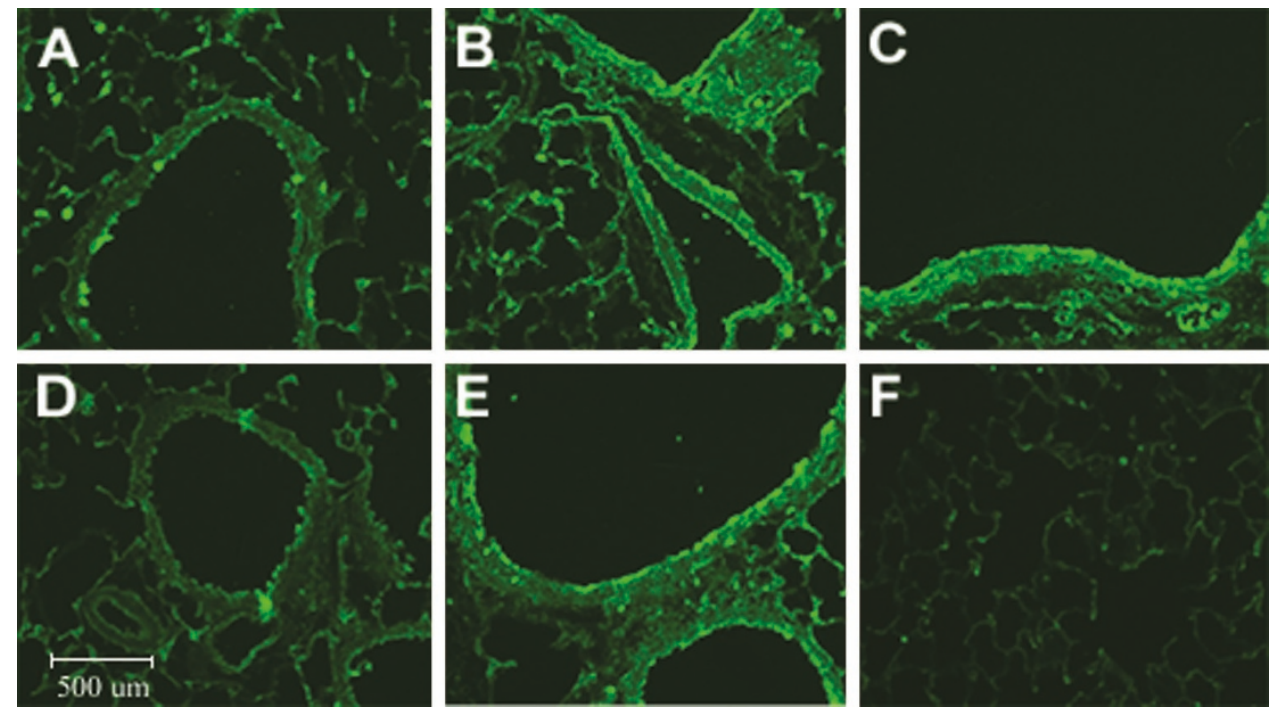

Figure 2. Representative photos of the immunohistochemical staining for SNO in lung tissue using polyclonal rabbit anti-SNO. (A) Room air control; $(B) 80 \%$ oxygen, $48 \mathrm{~h}$ of treatment; $(C) 80 \%$ oxygen plus $20 \mathrm{ppm}$ inhaled NO, $48 \mathrm{~h}$ of treatment; $(D)>95 \%$ oxygen, $48 \mathrm{~h}$ of treatment; $(E)>95 \%$ oxygen plus 20 ppm inhaled NO, 48 h of treatment; $(F)$ negative control treated with mercuric chloride. Magnification $\times 20$.

3-Nitrotyrosine adducts. Localization of 3-nitrotyrosine adducts in lung tissue is shown in Figure 3. Exposure to either $80 \%$ or $>95 \%$ oxygen concentration increased 3-nitrotyrosine staining in both bronchial and alveolar tissue. Compared with $>95 \%$ oxygen, animals treated with $80 \%$ oxygen had significantly higher staining, especially in alveolar tissue. Use of inhaled NO did not change the intensity of staining at any oxygen concentration. There was no difference in localization or intensity of the staining between animals treated for 24 or $48 \mathrm{~h}$.

NO metabolites. Figure 4 shows BAL measurements of vanadium-reducible NO metabolites, which principally reflect nitrate and nitrite, stable byproducts of NO reactivity and metabolism. The levels of these NO metabolites in BAL showed significant animal-to-animal variation without signifi- cant differences between treatment groups except for a decline in animals exposed to $80 \%$ oxygen for $48 \mathrm{~h}$. Use of inhaled $\mathrm{NO}$ failed to significantly change the concentration of nitrate and nitrite in the BAL fluid at either $80 \%$ or $>95 \%$ oxygen exposure, except for an increase seen at $48 \mathrm{~h}$ in $>95 \%$ oxygen exposure. In contrast to the BAL measurements, plasma nitrate and nitrite increased significantly with administration of inhaled NO in animals exposed to room air or $80 \%$ or $>95 \%$ oxygen.

Expression of NOS isoforms in the lung tissue. To investigate the mechanism for increased nitrosated and nitrated protein adducts detected in animals treated with $80 \%$ oxygen versus $>95 \%$ oxygen, expression of NOS isoforms was explored. Immunohistochemistry for iNOS demonstrated a marked increase in staining for iNOS in large peribronchial
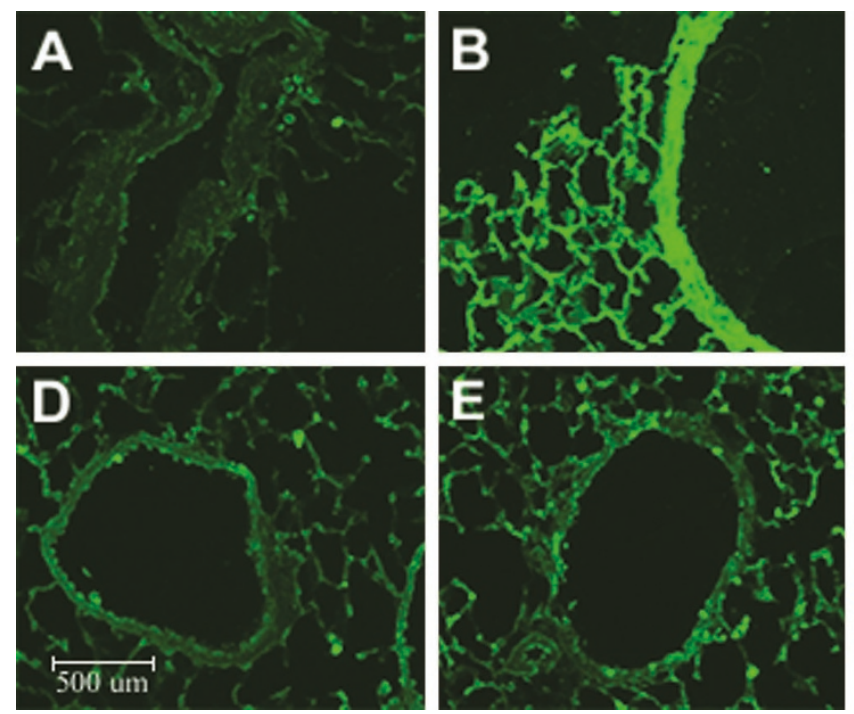
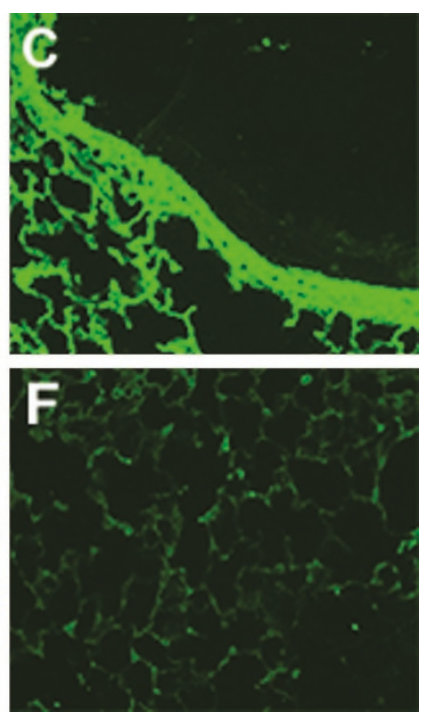

Figure 3. Representative photos of the immunohistochemical staining for 3-nitrotyrosine in lung tissue using polyclonal rabbit anti-3-nitrotyrosine. (A) Room air control; (B) 80\% oxygen, $48 \mathrm{~h}$ of treatment; $(C) 80 \%$ oxygen plus $20 \mathrm{ppm}$ inhaled NO, $48 \mathrm{~h}$ of treatment; $(D)>95 \%$ oxygen, $48 \mathrm{~h}$ of treatment; $(E)>95 \%$ oxygen plus $20 \mathrm{ppm}$ inhaled NO, $48 \mathrm{~h}$ of treatment; $(F)$ negative control treated with dithionite. Magnification $\times 20$. 


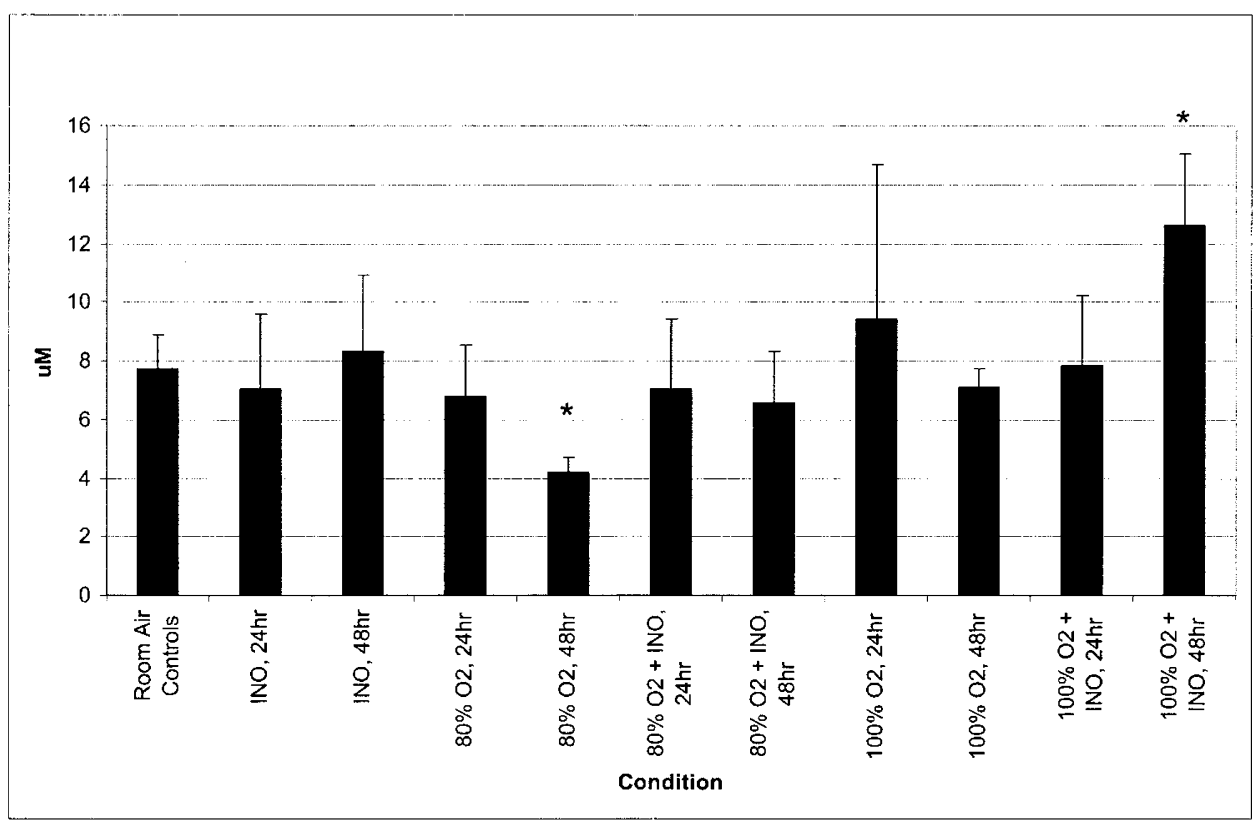

Figure 4. Quantification of total nitrite and nitrate in BAL fluid treated with $80 \%$ or $>95 \%$ oxygen with or without 20 ppm inhaled NO. Data are reported in $\mu \mathrm{M} .{ }^{*} p<0.05$ compared with room air controls by nonparametric rank sum test; $n=6$ in each group.

blood vessels in the $80 \%$ oxygen group consistent with previous studies (29). In contrast, there was no increase in staining in animals treated with $>95 \%$ oxygen (Fig. 5). Inhaled NO did not influence staining. Western blotting of frozen lung tissue for eNOS demonstrated no difference in expression between groups, and nNOS was undetectable by Western blot (data not shown).

Assessment of S-nitrosocysteine, 3-nitrotyrosine adducts, and vanadium-reduced $\mathrm{NO}$ metabolites during recovery at room air. A total of 12 animals were treated for $24 \mathrm{~h}$ with $>95 \%$ oxygen and $20 \mathrm{ppm}$ inhaled NO. Six animals were killed immediately after treatment as a control group; three animals recovered in room air for $24 \mathrm{~h}$ before sacrifice; and the last three animals recovered in room air for $48 \mathrm{~h}$ before sacrifice. Figure 6 shows the analysis on plasma and BAL samples taken from these animals. The levels of nitrate and nitrite in BAL showed no significant change in any treatment group over room air controls. However, plasma levels of nitrate and nitrite increased with treatment, then returned to baseline levels after $24 \mathrm{~h}$ of room air recovery. The levels of SNO adducts in BAL did not increase significantly until $48 \mathrm{~h}$ of recovery.

Immunohistochemical evaluation of the lung tissue is shown in Figure 7. Staining for SNO is increased in both bronchial and alveolar tissue after $24 \mathrm{~h}$ of $>95 \%$ oxygen and inhaled nitric oxide. Twenty-four hours into room air recovery, localization of SNO in bronchial tissue declined significantly below room air control levels $(p<0.05$ by digital image quantification using Metamorph software) and alveolar staining has returned to control levels. Forty-eight hours into the recovery period, SNO staining is significantly higher in both bronchial and alveolar tissue compared with the other three conditions. 3-Nitrotyrosine staining, also shown in Figure 7, was elevated in bronchial and alveolar tissue after $24 \mathrm{~h}$ of treatment and $24 \mathrm{~h}$ into the room air recovery period. Bronchial staining had begun to decrease $48 \mathrm{~h}$ into the recovery period, but still remained significantly elevated compared with room air controls. Alveolar staining had returned to near-control baseline levels.

\section{DISCUSSION}

NO plays multifaceted roles in most organ systems and cells. The pleotrophic biologic functions of $\mathrm{NO}$ are under the control of NO synthesis by the NOS, whereas specific chemical reactions of $\mathrm{NO}$ with proteins may regulate protein function and transduce downstream signaling events. The binding of NO to the reduced iron in the heme pocket of the soluble guanylate cyclase is the prototypical signaling interaction of NO with proteins. Recent data have also revealed that the reaction of NO and NO-derived oxides with reduced cysteine residues results in the formation of S-nitrosocysteine, which is proposed to preserve NO bioactivity as well as modulate the function of numerous proteins (20). Higher oxides of NO have also been shown to modify aromatic residues and specifically tyrosine residues forming 3-nitrotyrosine, which is considered a biomarker of NO-mediated stress and a potential modulator of protein function (30). The formation of higher oxides of NO such as dinitrogen dioxide, nitrogen dioxide, and peroxynitrite could also be facilitated by the presence of reactive oxygen species, metal catalysts, and peroxidases. Despite the reasonably well-defined chemical reactions that may lead to the formation of S-nitrosocysteine and 3-nitrotyrosine, the formation of these adducts in vivo under pathophysiological conditions has not been explored. By employing well-established models of hyperoxia, which alters the pulmonary levels of reactive oxygen species, this study investigated the formation 


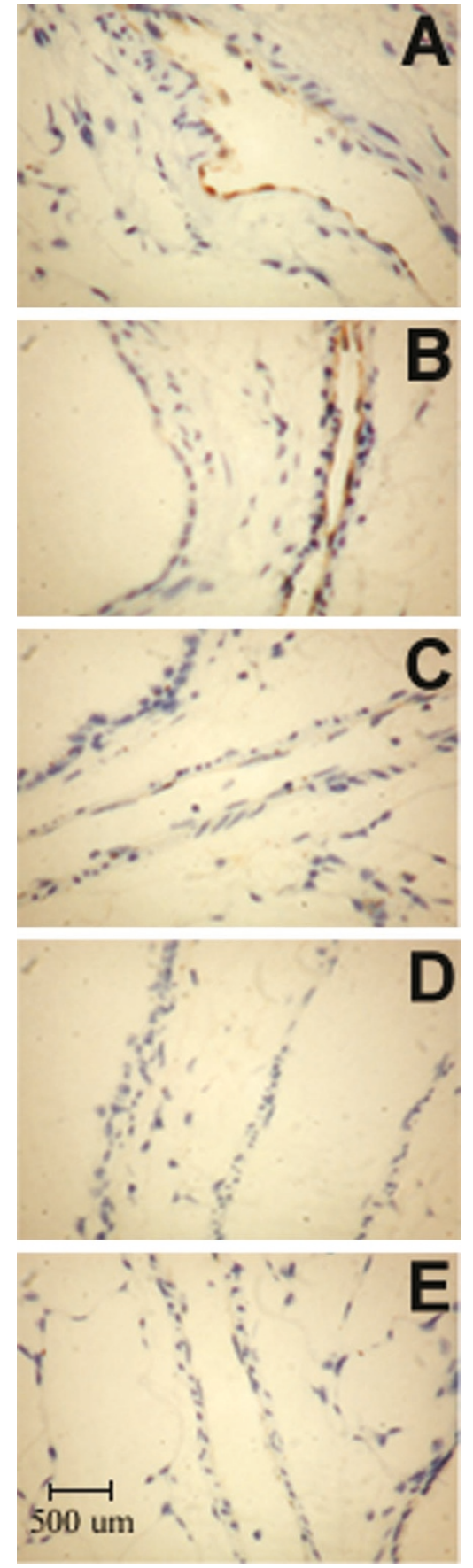

Figure 5. Representative photos of the immunohistochemical staining for iNOS in lung tissue using polyclonal rabbit anti-iNOS antibody (Transduction Laboratories). (A) $80 \%$ oxygen, $48 \mathrm{~h}$ of treatment; $(B) 80 \%$ oxygen plus 20 ppm inhaled NO, $48 \mathrm{~h}$ of treatment; $(C)>95 \%$ oxygen, $48 \mathrm{~h}$ treatment; $(D)$ $>95 \%$ oxygen plus $20 \mathrm{ppm}$ inhaled NO, $48 \mathrm{~h}$ treatment; $(E)$ room air control.

of SNO and 3-nitroyrosine adducts in the presence or absence of inhaled NO.

The data indicated that exposure to $80 \%$ oxygen led to an increase in SNO levels in BAL and lung tissue indicating that this oxygen tension is conducive to nitrosative chemistry. Expression of iNOS was increased in the pulmonary vessels, and the associated increase in NO concentration is evident in part by the elevated SNO levels. Proteins with cysteine(s) modified to SNO potentially provide a stable pool of bioactive NO adducts mediating some biologic activity of endogenous NO, regulating airway and pulmonary artery tone (31-33). Rats exposed to $>95 \%$ oxygen, however, had a decrease in $\mathrm{SNO}$ in BAL and tissue. This could result from either increased destruction of SNO, or a suppression of nitrosative chemistry, specifically the availability of reduced cysteine residues. We speculate that exposure to $95 \%$ oxygen (lethal in nearly $50 \%$ of rats by $60 \mathrm{~h}$ of exposure) will increase the oxidative burden and therefore the oxidation of cysteine residues when compared with $80 \%$ oxygen exposure (a condition that is not lethal to rats until $7 \mathrm{~d}$ of continuous exposure). Alternatively, under $>95 \%$ oxygen, nitrosated proteins might be rapidly turned over through proteolytic or enzymatic processes. Expression of iNOS was not increased in these animals, and, as a result, the endogenous concentration of $\mathrm{NO}$ was likely lower than in the rats exposed to $80 \%$ oxygen. Inhaled NO leads to increased levels of nitrosation, lending further support to the concept that NO concentration drives nitrosation of proteins. The different levels of nitrosated proteins noted under varying oxygen tensions may have clinical correlates. Recently, Schreiber et al. (7) demonstrated a decrease in the incidence of chronic lung disease and mortality with the administration of inhaled NO to premature infants. Interestingly, a post hoc analysis found that infants with a lower oxygenation index were the patients most likely to benefit from inhaled NO (7). We speculate that varying oxygen tensions in the clinical setting may alter the metabolic fate of $\mathrm{NO}$, thereby influencing the therapeutic effect. Conditions that favor the formation of SNO, which could support pulmonary physiologic functions (32), are likely to be beneficial and inhaled NO may sustain formation of SNO adducts even in the presence of highly oxidizing conditions as seen in the rats exposed to $>95 \%$ oxygen.

As seen in prior studies (13), use of inhaled NO at $20 \mathrm{ppm}$ not only increased SNO production, it did not significantly increase the formation of 3-nitrotyrosine adducts. 3-Nitrotyrosine was elevated in rats exposed to either $80 \%$ or $>95 \%$ oxygen, indicating that hyperoxia enhances formation of nitrative species, consistent with results reported in other models of hyperoxia $(13,17,34)$. There is mounting evidence that inflammatory cells are largely responsible for nitration in hyperoxic conditions. Recently Jankov and colleagues (14) treated newborn rats with $60 \%$ oxygen and demonstrated injury and elevated 3-nitrotyrosine levels in lung tissue. Administration of gadolinium, which prevents infiltration of the lung with macrophages, attenuated injury and nitration, demonstrating that hyperoxia creates an inflammatory state in which macrophages are a probable source of nitrating species. Narasaraju and colleagues (17) documented increased numbers of activated macrophages in the lungs of rats exposed to $>95 \%$ oxygen for $>48 \mathrm{~h}$. In a separate experiment, co-culture of macrophages and neutrophils from these animals with rat epithelial L2 cells generated nitrated proteins. Interestingly, 3-nitrotyrosine has also been detected in iNOS knockout mice exposed to $>95 \%$ oxygen, indicating that 3-nitrotyrosine formation is not solely dependent on iNOS (35). Results presented here are consistent with these findings in that both $80 \%$ and $>95 \%$ oxygen created 


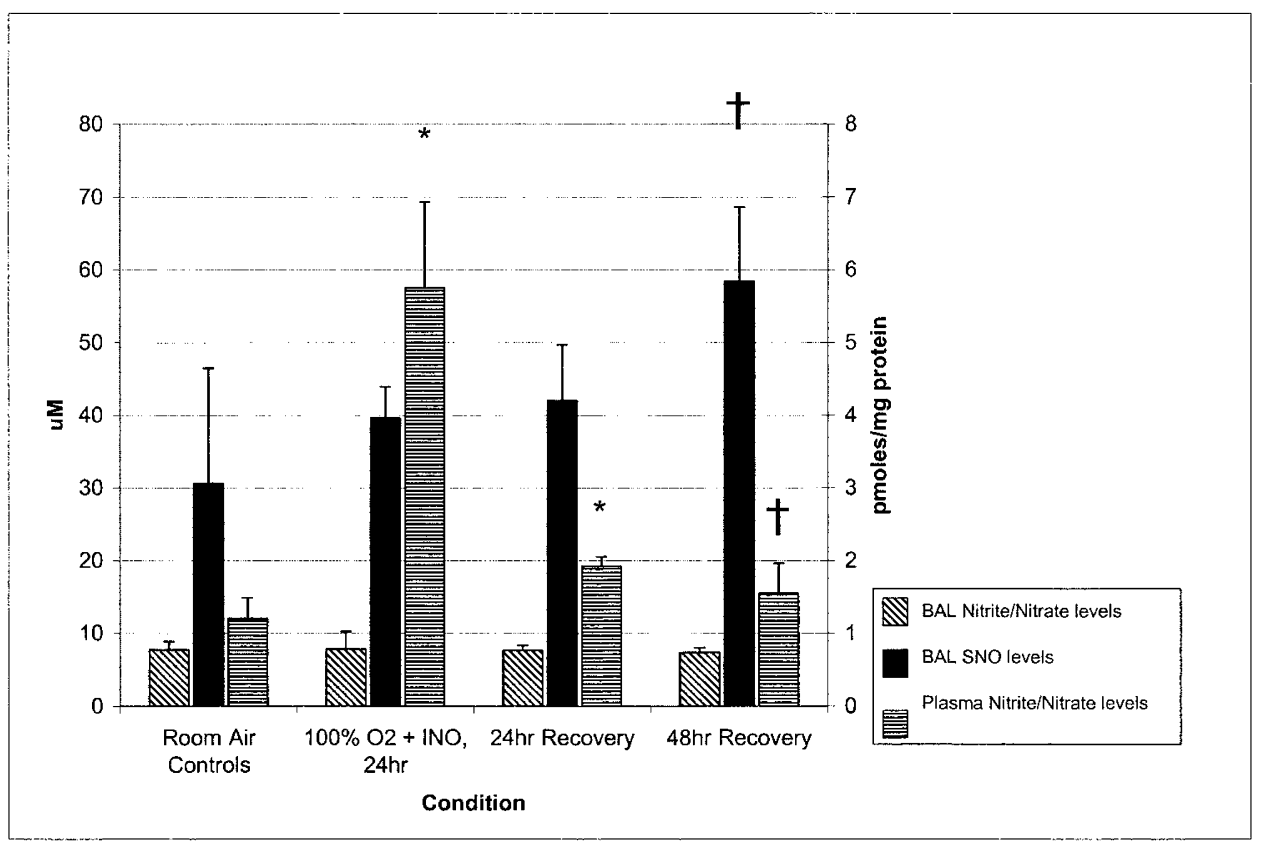

Figure 6. Quantification of NO-mediated metabolites and adducts in room air controls, animals treated with $>95 \%$ oxygen plus 20 ppm inhaled NO for $24 \mathrm{~h}$ $(n=6)$, and room air recovery animals ( $n=3$ at $24 \mathrm{~h}$ recovery and $n=3$ at $48 \mathrm{~h}$ recovery). Diagonally hatched bars represent total nitrite and nitrate levels in BAL fluid in $\mu \mathrm{M}$. Solid bars represent S-nitrosocysteine and low-molecular-weight S-nitrosothiol measurements in BAL fluid in pmol/mg of protein. Horizontally hatched bars represent total nitrite and nitrate levels in plasma in $\mu \mathrm{M} .{ }^{*} p<0.05$ compared with room air controls by nonparametric rank sum test; $\dagger p<0.05$ compared with $>95 \%$ oxygen plus 20 ppm inhaled NO animals by nonparametric rank sum test.
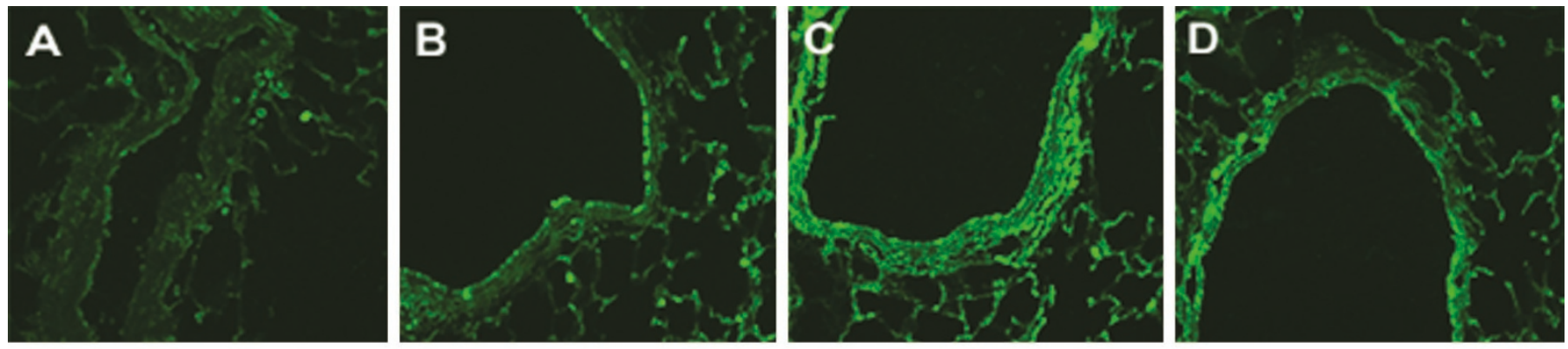

\section{3-Nitrotyrosine Staining}
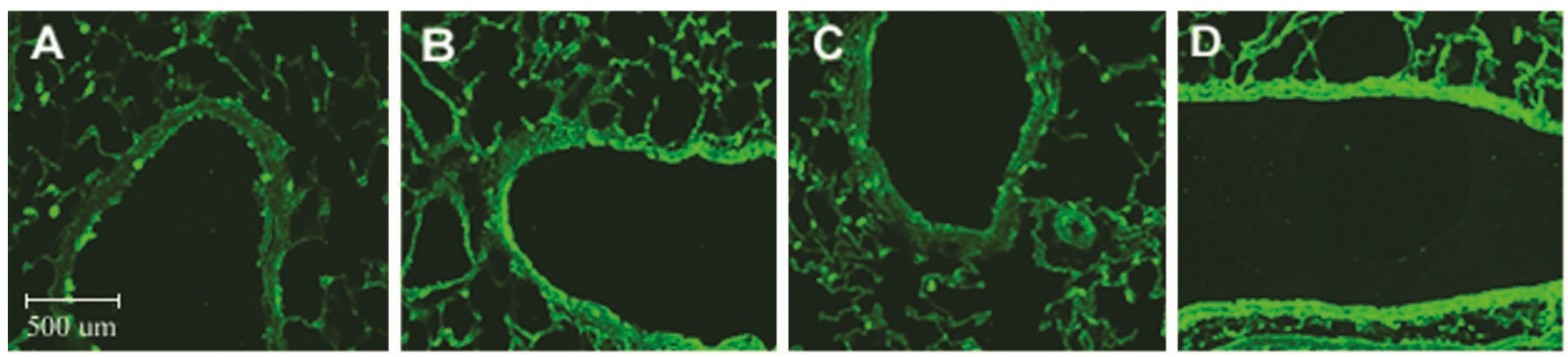

\section{S-Nitrosocysteine Staining}

Figure 7. Representative photos of the immunohistochemical staining for $\mathrm{SNO}$ and 3-nitrotyrosine in lung tissue using polyclonal rabbit anti-SNO or anti-3-nitrotyrosine antibody. $(A)$ Room air controls; $(B)>95 \%$ oxygen plus 20 ppm inhaled NO, 24 h of treatment; $(C)$ 24-h room air recovery; $(D)$ 48-h room air recovery. Magnification $\times 20$.

enhanced nitrative conditions even though iNOS expression was elevated only in rats exposed to $80 \%$ oxygen. Oxidative stress and inflammation appear to be the primary driving forces for formation of nitrotyrosine, and the addition of exogenous $\mathrm{NO}$ in the form of inhaled NO has little impact on the formation of nitrating species. 
The results from the room air recovery animals suggest that the level of NO-mediated protein adducts return to baseline in a time-dependent fashion. NO metabolite levels returned rapidly to baseline after administration of hyperoxia and inhaled NO, consistent with other studies investigating sepsis and endogenous NO $(36,37)$. SNO and 3-nitrotyrosine levels, though, continued to show changes from baseline up to $48 \mathrm{~h}$ after removal of $>95 \%$ oxygen and inhaled NO. The ability to metabolize and properly remove proteins modified by nitrosation and nitration may be critical for restoring normal biologic function. Recent studies with mice deficient in the ability to metabolize S-nitrosoglutathione were hypotensive and showed increased levels of SNO adducts in red blood cells (38). Similarly it has been suggested that inappropriate accumulation of tyrosine-nitrated proteins may lead to cellular dysfunction and triggering of immune responses (30).

Overall, hyperoxia appears to drive nitration of proteins through infiltration of inflammatory cells and an associated increase in the formation of nitrative species. Nitrosation, however, may be elevated or depressed depending on the specific oxygen tension and appears to be driven by $\mathrm{NO}$ concentration. An increase in expression of iNOS or provision of exogenous $\mathrm{NO}$ in the form of inhaled $\mathrm{NO}$ leads to an increase in nitrosated proteins. This may be an important mechanism for the therapeutic effect of inhaled NO in conditions requiring high oxygen tensions such as persistent pulmonary hypertension of the neonate.

\section{REFERENCES}

1. Clark RH, Kueser TJ, Walker MW, Southgate WM, Huckaby JL, Perez JA, Roy BJ, Keszler M, Kinsella JP 2000 Low-dose nitric oxide therapy for persistent pulmonary hypertension of the newborn. Clinical Inhaled Nitric Oxide Research Group. N Engl J Med 342:469-474

2. The Neonatal Inhaled Nitric Oxide Study Group 1997 Inhaled nitric oxide in full-term and nearly full-term infants with hypoxic respiratory failure. N Engl J Med 336:597604

3. Kinsella JP, Truog WE, Walsh WF, Goldberg RN, Bancalari E, Mayock DE, Redding GJ, deLemos RA, Sardesai S, McCurnin DC, Moreland SG, Cutter GR, Abman SH 1997 Randomized, multicenter trial of inhaled nitric oxide and high-frequency oscillatory ventilation in severe, persistent pulmonary hypertension of the newborn. J Pediatr 131:55-62

4. Davidson D, Barefield ES, Kattwinkel J, Dudell G, Damask M, Straube R, Rhines J, Chang CT 1998 Inhaled nitric oxide for the early treatment of persistent pulmonary hypertension of the term newborn: a randomized, double-masked, placebo-controlled, dose-response, multicenter study. The I-NO/PPHN Study Group. Pediatrics 101:325334

5. Kinsella JP, Walsh WF, Bose CL, Gerstmann DR, Labella JJ, Sardesai S, WalshSukys MC, McCaffrey MJ, Cornfield DN, Bhutani VK, Cutter GR, Baier M, Abman SH 1999 Inhaled nitric oxide in premature neonates with severe hypoxaemic respiratory failure: a randomised controlled trial. Lancet 354:1061-1065

6. Banks BA, Seri I, Ischiropoulos H, Merrill J, Rychik J, Ballard RA 1999 Changes in oxygenation with inhaled nitric oxide in severe bronchopulmonary dysplasia. Pediatrics 103:610-618

7. Schreiber MD, Gin-Mestan K, Marks JD, Huo D, Lee G, Srisuparp P 2003 Inhaled nitric oxide in premature infants with the respiratory distress syndrome. N Engl J Med 349:2099-2107

8. Ischiropoulos H, Zhu L, Chen J, Tsai M, Martin JC, Smith CD, Beckman JS 1992 Peroxynitrite-mediated tyrosine nitration catalyzed by superoxide dismutase. Arch Biochem Biophys 298:431-437

9. Beckman JS, Koppenol WH 1996 Nitric oxide, superoxide, and peroxynitrite: the good, the bad, and ugly. Am J Physiol 271:C1424-C1437

10. Gow A, Duran D, Thom SR, Ischiropoulos H 1996 Carbon dioxide enhancement of peroxynitrite-mediated protein tyrosine nitration. Arch Biochem Biophys 333:42-48

11. Royall JA, Kooy NW, Beckman JS 1995 Nitric oxide-related oxidants in acute lung injury. New Horiz 3:113-122

12. Crapo JD, Barry BE, Foscue HA, Shelburne J 1980 Structural and biochemical changes in rat lungs occurring during exposures to lethal and adaptive doses of oxygen. Am Rev Respir Dis 122:123-143
13. Lorch SA, Foust III R, Gow A, Arkovitz M, Salzman AL, Szabo C, Vayert B, Geffard M, Ischiropoulos H 2000 Immunohistochemical localization of protein 3-nitrotyrosine and S-nitrosocysteine in a murine model of inhaled nitric oxide therapy. Pediatr Res 47:798-805

14. Jankov RP, Johnstone L, Luo X, Robinson BH, Tanswell AK 2003 Macrophages as a major source of oxygen radicals in the hyperoxic newborn rat lung. Free Radic Biol Med 35:200-209

15. van der Vliet A, Eiserich JP, Halliwell B, Cross CE 1997 Formation of reactive nitrogen species during peroxidase-catalyzed oxidation of nitrite. A potential additional mechanism of nitric oxide-dependent toxicity. J Biol Chem 272:7617-7625

16. Brennan ML, Wu W, Fu X, Shen Z, Song W, Frost H, Vadseth C, Narine L, Lenkiewicz E, Borchers MT, Lusis AJ, Lee JJ, Lee NA, Abu-Soud HM, Ischiropoulos H, Hazen SL 2002 A tale of two controversies: defining both the role of peroxidases in nitrotyrosine formation in vivo using eosinophil peroxidase and myeloperoxidasedeficient mice, and the nature of peroxidase-generated reactive nitrogen species. J Biol Chem 277:17415-17427

17. Narasaraju TA, Jin N, Narendranath CR, Chen Z, Gou D, Liu L 2003 Protein nitration in rat lungs during hyperoxia exposure: a possible role of myeloperoxidase. Am J Physiol Lung Cell Mol Physiol 285:L1037-L1045

18. Gutierrez HH, Nieves B, Chumley P, Rivera A, Freeman BA 1996 Nitric oxide regulation of superoxide-dependent lung injury: oxidant-protective actions of endogenously produced and exogenously administered nitric oxide. Free Radic Biol Med 21:43-52

19. Howlett CE, Hutchison JS, Veinot JP, Chiu A, Merchant P, Fliss H 1999 Inhaled nitric oxide protects against hyperoxia-induced apoptosis in rat lungs. Am J Physiol 277:L596-L605

20. Stamler JS, Lamas S, Fang FC 2001 Nitrosylation. The prototypic redox-based signaling mechanism. Cell 106:675-683

21. Molina y Vedia L, McDonald B, Reep B, Brune B, Di Silvio M, Billiar TR, Lapetina EG 1992 Nitric oxide-induced S-nitrosylation of glyceraldehyde-3-phosphate dehydrogenase inhibits enzymatic activity and increases endogenous ADP-ribosylation. J Biol Chem 267:24929-24932

22. Xu L, Eu JP, Meissner G, Stamler JS 1998 Activation of the cardiac calcium release channel (ryanodine receptor) by poly-S-nitrosylation. Science 279:234-237

23. Kim YM, Talanian RV, Billiar TR 1997 Nitric oxide inhibits apoptosis by preventing increases in caspase-3-like activity via two distinct mechanisms. J Biol Chem 272:31138-31148

24. Mannick JB, Hausladen A, Liu L, Hess DT, Zeng M, Miao QX, Kane LS, Gow AJ, Stamler JS 1999 Fas-induced caspase denitrosylation. Science 284:651-654

25. Banks BA, Ischiropoulos H, McClelland M, Ballard PL, Ballard RA 1998 Plasma 3-nitrotyrosine is elevated in premature infants who develop bronchopulmonary dysplasia. Pediatrics 101:870-874

26. Viera L, Ye YZ, Estevez AG, Beckman JS 1999 Immunohistochemical methods to detect nitrotyrosine. Methods Enzymol 301:373-381

27. Geffard M, Dulluc J, Rock AM 1985 Antisera against the indolealkylamines: tryptophan, 5-hydroxytryptophan, 5-hydroxytryptamine, 5-methoxytryptophan, and 5-methoxytryptamine tested by an enzyme-linked immunosorbent assay method. J Neurochem 44:1221-1228

28. Fries DM, Paxinou E, Themistocleous M, Swanberg E, Griendling KK, Salvemini D, Slot JW, Heijnen HF, Hazen SL, Ischiropoulos H 2003 Expression of inducible nitric-oxide synthase and intracellular protein tyrosine nitration in vascular smooth muscle cells: role of reactive oxygen species. J Biol Chem 278:22901-22907

29. Cucchiaro G, Tatum AH, Brown MC, Camporesi EM, Daucher JW, Hakim TS 1999 Inducible nitric oxide synthase in the lung and exhaled nitric oxide after hyperoxia. Am J Physiol 277:L636-L644

30. Ischiropoulos H 2003 Biological selectivity and functional aspects of protein tyrosine nitration. Biochem Biophys Res Commun 305:776-783

31. Moya MP, Gow AJ, McMahon TJ, Toone EJ, Cheifetz IM, Goldberg RN, Stamler JS 2001 S-nitrosothiol repletion by an inhaled gas regulates pulmonary function. Proc Natl Acad Sci U S A 98:5792-5797

32. Gaston B, Reilly J, Drazen JM, Fackler J, Ramdev P, Arnelle D, Mullins ME, Sugarbaker DJ, Chee C, Singel DJ, Loscalzo J, Stamler J 1993 Endogenous nitrogen oxides and bronchodilator S-nitrosothiols in human airways. Proc Natl Acad Sci U S A 90:10957-10961

33. Bannenberg G, Xue J, Engman L, Cotgreave I, Moldeus P, Ryrfeldt A 1995 Characterization of bronchodilator effects and fate of S-nitrosothiols in the isolated perfused and ventilated guinea pig lung. J Pharmacol Exp Ther 272:1238-1245

34. Haddad IY, Pataki G, Hu P, Galliani C, Beckman JS, Matalon S 1994 Quantitation of nitrotyrosine levels in lung sections of patients and animals with acute lung injury. J Clin Invest 94:2407-2413

35. Kobayashi H, Hataishi R, Mitsufuji H, Tanaka M, Jacobson M, Tomita T, Zapol WM, Jones RC 2001 Antiinflammatory properties of inducible nitric oxide synthase in acute hyperoxic lung injury. Am J Respir Cell Mol Biol 24:390-397

36. Wong HR, Carcillo JA, Burckart G, Kaplan SS 1996 Nitric oxide production in critically ill patients. Arch Dis Child 74:482-489

37. Baines PB, Stanford S, Bishop-Bailey D, Sills JA, Thomson AP, Mitchell JA, Fear SC, Hart CA, Petros AJ 1999 Nitric oxide production in meningococcal disease is directly related to disease severity. Crit Care Med 27:1187-1190

38. Liu L, Yan Y, Zeng M, Zhang J, Hanes MA, Ahearn G, McMahon TJ, Dickfeld T, Marshall HE, Que LG, Stamler JS 2004 Essential roles of s-nitrosothiols in vascular homeostasis and endotoxic shock. Cell 116:617-628 